\title{
Brevísimas nociones de Analogía Castellana (1891) de Julio Severiano Hernández y García: un texto para la enseñanza de la gramática escolar en Santiago de $\mathrm{Cuba}^{1}$
}

\author{
Arcilio Bonne Bravo* \\ Irina Bidot Martinez \\ Mercedes Causse Cathcart \\ Facultad de Humanidades \\ Universidad de Oriente, Cuba
}

\begin{abstract}
Resumen
La gramática castellana se instaura como disciplina escolar en España y América en 1813, momento en que se generaliza su estudio, pues anteriormente era de enseñanza obligatoria la gramática latina. Este trabajo se propone realizar un análisis estructural y de contenido del texto Brevísimas nociones de Analogía Castellana (1891) teniendo en cuenta el contexto decimonónico de la enseñanza escolar de esta disciplina en Cuba.
\end{abstract}

\footnotetext{
1 Este trabajo ha sido apoyado por la Cooperación para el Desarrollo Belga, a través de VLIR-UOS (Consejo flamenco interuniversitario de cooperación para el desarrollo), en el contexto del programa de cooperación institucional universitario con la Universidad de Oriente, Santiago de Cuba, Cuba.

* Para correspondencia, dirigirse a: Mercedes Causse Cathcart: mechy@fch.uo.edu. cu; Arcilio Bonne Bravo: arci@fch.uo.edu.cu; Irina Bidot Martínez: bidot@fch.uo.edu.cu. Patricio Lumumba s/n. Santiago de Cuba, Cuba. CP 90300
} 
El libro fue editado en Santiago de Cuba en 1891 por Julio Severiano Hernández y García, "Maestro Titular de enseñanza incompleta" y Director del Colegio privado San Severiano, y si bien sigue en lo formal las peculiaridades que en la época tenían los manuales de esta materia, también destaca, a diferencia de aquellos, por el uso de ejemplos propios del coloquio y contextualizados en el habla de la región en aquella época.

Palabras clave: gramática española, historiografía lingüística, analogía.

\author{
BRIEF NOTIONS OF CASTILIAN ANALOGY (1891) From JuLIO \\ SEveriano Hernández y García: a teXt to TEACH SCHOOL \\ Grammar in Santiago de Cuba"
}

\begin{abstract}
Castilian grammar became a teaching discipline in Spain and Latin America in 1813, when its study was generalized; before that, Latin grammar was mandatory. This paper aims at making a structural and content analysis of the text Brevisimas nociones de Analogía Castellana (1891) taking into account the context of the teaching of this discipline in Cuba.

The book was edited in Santiago de Cuba in 1891 by Julio Severiano Hernández y García, "Full Professor of incomplete teaching" and Director of the private college San Severiano; the book follows the peculiarities of the manuals of that time, but it also stands out, unlike others, by the use of example belonging to the colloquial level in the language of the region at the time.
\end{abstract}

Keywords: Castilian grammar, linguistic historiography, analogy.

Recibido: 16/03/15

Aceptado: 31/07/15

\title{
1. INTRODUCCIÓN
}

La gramática ha sido una disciplina presente en toda la enseñanza escolar. Antes de bien avanzado el siglo XVIII, tanto en España como en América estaba instaurado el conocimiento de la gramática latina, en detrimento del de la lengua española que se hablaba en tan vasto territorio. El 23 de 
junio de 1768, Carlos III promulga e institucionaliza, por Real Cédula, la reacción ilustrada en contra del latín como lengua de la enseñanza, y en 1813 se elabora el Informe de Quintana donde se generaliza definitivamente el castellano en el ámbito educativo. En todo este proceso es importante destacar la labor de la RAE como entidad normalizadora y de codificación lingüística, sobre todo a partir de la aprobación de los Estatutos del Colegio Académico de Primeras Letras en 1780, también bajo el reinado de Carlos III (García 2005). De esta forma se instaura la gramática española como disciplina escolar en España y en las diferentes colonias americanas de las que Cuba formaba parte.

En este trabajo nos proponemos analizar desde el punto de vista de la estructura y del contenido el texto Brevísimas nociones de Analogía Castellana (1891), teniendo en cuenta el contexto decimonónico de la enseñanza escolar de esta disciplina en Cuba. Para ello se toma en consideración su finalidad u objetivo, la técnica empleada para su estructuración, así como las partes que la conforman. La obra se editó en Santiago de Cuba en 1891. Su autor, Julio Severiano Hernández y García, según se declara en la carátula del libro, fue "Maestro Titular de enseñanza incompleta" y Director del Colegio privado San Severiano. Fue encontrado en la Biblioteca provincial Elvira Cape de la ciudad de Santiago de Cuba, y dentro del proyecto de investigación entre universidades belgas y la Universidad de Oriente, ha sido rescatado para su conservación y estudio.

Este texto ${ }^{3}$ estaba destinado a la enseñanza primaria, nivel de la escuela dirigida por el autor, de la cual también era dueño, y se orienta fundamentalmente al aprendizaje de la gramática (no así a la escritura).

2 Este tipo de enseñanza estaba dirigido a las personas pobres y especialmente a las de piel negra; el nivel era primario.

3 El documento que aquí se presenta corresponde solo a la parte primera: Analogía; se encontró en los archivos digitales de la Biblioteca Nacional de España, Nuevas tablas de cuentas para párvulos (1892), donde se promueven para su compra por parte de los estudiantes, la segunda edición corregida y aumentada de Brevísimas nociones de Analogía castellana (1892) (al cual no hemos podio acceder) y el Cuaderno de calificaciones diarias (s.f.). 


\section{DESARROLLO}

La tradición de los estudios lingüísticos en Cuba se remonta a finales del siglo XVIII ${ }^{4}$ y se caracteriza, por un lado, en opinión de Rodolfo Alpízar (1989), en que quienes se dedicaron a estos quehaceres fueron aficionados, con excepción de Juan Miguel Dihigo y Mestre (1886-1952), quien no dejó discípulos que continuaran sus ideas, a pesar de haber desarrollado una labor meritoria en el campo de la ciencia; y por otro, en que los estudios han estado dirigidos hacia el español de Cuba, lo cual explica que el comienzo de las preocupaciones entre los cubanos estuvo encaminado a la búsqueda de los matices diferenciadores del español de uso en la isla, en relación con el de la Península.

A pesar del desarrollo que han alcanzado en la actualidad los estudios lingüísticos en el país, aún no ha habido un progreso destacado hacia las investigaciones historiográficas, tal y como señala Alpízar en el trabajo citado, quien considera, además, que "la historia de la lingüística cubana está aún por escribir" (ibíd. 3). A tantos años de este texto tal situación todavía está pendiente, en nuestra consideración, aunque es bueno destacar que se han dado pasos para revertirla, pero aún los estudios están dispersos y se limitan a personalidades y obras, no al establecimiento de líneas de investigación y análisis en este campo ${ }^{5}$.

De acuerdo con eso, el libro de este autor mantiene su vigencia, al menos en su carácter sistematizador e inicial. En el análisis de los estudios sobre el español de Cuba realizados en el país desde 1795, se observa que la mayor atención la han recibido las cuestiones relacionadas con el léxico, la fonética, la morfología, la prosodia, la pronunciación, etc. Sin embargo,

4 Los primeros documentos que expresan inquietudes sobre la peculiaridades de la variante cubana del español datan de 1795, y son: "Memoria sobre los defectos de la pronunciación y escritura de nuestro idióma y medios de corregirlos" (sic), de fray Pedro Espínola, y la "Memoria que promueve la edicion de un Diccionario provincial de la Isla de Cuba" (sic), de fray José María Peñalver. Ambos documentos se elaboraron por miembros de la sección denominada Clase de Ciencias y Arte de la Sociedad Económica de La Habana (fundada en 1793) y resulta evidente su importancia histórica, cultural y lingüística para la conformación de la historia de la lingüística en Cuba.

5 Sirvan de ejemplo, el trabajo del mismo Alpízar, Apuntes para una historia de la lingüística en Cuba (1989), recopilación de textos de interés lingüístico de autores cubanos de los siglos XVIII y XIX, La voz de los otros (2010), de Marlen Domínguez, compilación de trabajos sobre autores que escribieron y reflexionaron sobre estos temas, y estudios históricos realizados por la propia autora, y de Rafael Martínez, Juan Miguel Dihigo: gran lingüista cubano (1983). 
poco interés recibieron los estudios sintácticos, a pesar de la gran cantidad de gramáticas que se publicaron, sobre todo en el siglo XIX, en las cuales no se prestó atención a la sintaxis del español de Cuba (ídem), a pesar del marcado interés mostrado por algunos de los autores en el establecimiento y la descripción de las diferencias entre las variables peninsular y cubana.

La prolijidad en la elaboración de gramáticas, en opinión de Marlen Domínguez, "puede ser evidencia del carácter y el nivel de esos estudios en la época y de sus fuentes principales" (2010: 139). En tal sentido, la autora hace referencia a los datos ofrecidos por Juan M. Dihigo en 1916, quien contabiliza 49, de las cuales afirma solo se han localizado en Cuba 16, del período 1831-1901.

El objetivo de estos textos "era vulgarizar, explicar y ejemplificar la gramática de la Academia, no la comprobación, ni mucho menos el análisis, de los fenómenos peculiares de la lengua en Cuba" (ibíd. 104). Singular resulta en esta enumeración la obra del presbítero Félix Varela, quien desde 1817 realizó interesantes comentarios gramaticales, que en opinión de Alpízar lo distinguen de otros autores; sirva como ejemplo lo que dijo sobre el nombre:

El nombre no debe definirse, pues todos los niños saben lo que es; pero si hay mucho empeño en hacerlo, diríamos que nombre es la palabra con que indicamos alguna cosa o sus propiedades. En esta definición está comprendida la idea de palabra, y de la de su aplicación á las cosas, que es lo que la constituye nombre, y al mismo tiempo se entiende tanto á los sustantivos como á los adjetivos, según lo quiere el autor, pues sustantivo no es, sino un nombre que significa una sustancia, y adjetivo el que significa una propiedad. Esta definición es la menos mala que hemos podido discurrir (apud, ibíd. 105).

Un análisis de estas obras no deja de ser interesante e importante para los estudios gramaticográficos en el país, por cuanto su examen detallado puede revelar aspectos significativos para la historiografía lingüística en Cuba.

Por otra parte, en función de una contextualización desde el punto de vista diacrónico, se debe tener presente también que durante varios siglos Cuba siempre tuvo una condición relegada en relación con los grandes virreinatos del continente. Los centros de enseñanza en la isla tuvieron una precaria existencia hasta finales del siglo XVIII y su fomento siempre fue de incumbencia de las órdenes religiosas; por lo que las clases que se daban a niños y jóvenes respondían a los intereses del clero, con fuerte presencia del latín, los rezos y escasos elementos relacionados con las cuentas matemáticas.

Santiago de Cuba también padeció la precariedad de la enseñanza; su patriciado criollo prácticamente no tenía interés por la instrucción hasta 
despuntar el siglo XVIII ${ }^{6}$. Sin embargo, resulta significativo el hecho de que en la temprana fecha del 14 de abril de 1722 se creó el Seminario San Basilio Magno, la más antigua de las instituciones cubanas de estudios superiores $^{7}$, pero con las limitaciones escolásticas de la época, las cuales solo pudieron ser reformadas a partir de $1781^{8}$, con la incorporación, entre otros, de dos maestros de gramática (Portuondo y Rovira 2000: 46); todo ello dentro de los aires del Iluminismo que "permitieron la creación de la Sociedad Patriótica de Amigos del País en $1788^{9}$ que, desde su fomento, se preocupó por el establecimiento de una escuela de primeras letras, o los que conminaban a la introducción de la imprenta" (ibíd. 47).

Las gramáticas que se han conservado en nuestro país, de manera general, responden al tipo de gramática escolar en forma de diálogo que comienza a desarrollarse en el mundo de habla hispana desde finales del siglo XVIII ${ }^{10} \mathrm{y}$ que se destina a niveles iniciales de formación con el objetivo de ofrecer de la manera más sencilla posible un contenido gramatical a través del método de pregunta-respuesta en forma de intercambio comunicativo entre el sabio maestro y el alumno, que siempre sabe la respuesta.

Es una gramática que se desarrolla a partir de la Ilustración, momento en el que por primera vez se produce la aceptación social del aprendizaje de la lengua española como una necesidad, en detrimento de la gramática

6 Ya en 1706, algunos miembros del patriciado aportaron hasta $\$ 6800,00$ en imposiciones, con sus réditos, para sostener clases de Gramática Latina y Filosofía en el convento de San Francisco en acuerdo con fray Salvador Bueno, de esta orden (Portuondo y Rovira 2000: 21).

7 Solo hasta 1729 se funda la Real y Pontificia Universidad de San Gerónimo, en el convento de San Juan de Letran de La Habana, sin presencia, por supuesto, de ninguna cátedra de gramática castellana y con un inmenso atraso en los estudios en comparación con el grado alcanzado por universidades europeas e incluso americanas. Años más tarde, en 1773, se creó el Seminario San Carlos y San Ambrosio, también en La Habana, ya con menos apego al escolasticismo y bajo la importante figura del obispo criollo Santiago Hechavarría y Elguezúa, curiosamente ex alumno del San Basilio, nativo de la villa santiaguera y abanderado de la Ilustración.

8 Esta reforma dentro del Seminario se debió a Santiago Hechavarría y Elguezúa, quien en una visita pastoral a su ciudad natal en 1774 se propuso renovar el colegio seminario con el fin de ponerlo al mismo nivel que el de La Habana.

9 En 1793 se funda en la Habana la Sociedad Económica (Sociedad Patriótica de La Havana). Nótese que una vez más, Santiago de Cuba se adelantaba en la gestación de otro importante centro cultural.

10 En este siglo, la actividad gramatical española desde la propia Metrópoli presenta diferencias sustanciales con relación al periodo anterior: se produce un notable incremento del número de tratados gramaticales y se modifica sensiblemente la doctrina que fundamenta la descripción gramatical; hechos atribuidos a las nuevas circunstancias de orden sociocultural y educativo que configuran el paradigma intelectual de la España de la Ilustración, por contraposición al del Barroco (Martínez 2011: 572). 
latina, prioritaria hasta ese momento, en los currículos escolares. "A ello obedece el salto cuantitativo experimentado por la gramática ${ }^{11}$ en esta época respecto a la etapa anterior y, así mismo, explica que, a diferencia de la gramática del Barroco, ya no esté vinculada casi exclusivamente a una finalidad propedéutica y se desarrolle bajo el apoyo institucional" (Martínez 2011: 574).

Desde el contexto legal y partiendo de la Metrópoli, la enseñanza de la gramática española, a partir del primer cuarto del siglo XIX, se instaura de manera autónoma en relación con la lengua latina, en los distintos niveles de enseñanza, y a partir de 1855 y de manera efectiva desde 1857, se impone el uso de las obras de la Real Academia Española en lo referente a la gramática y la ortografía, editándose "a partir de la Ley de Instrucción pública de Claudio Moyano, en 1857, Compendios de la Gramática, Epítomes de Analogía y Sintaxis y, antes, ya en 1844, Prontuario de Ortografia" (Zamora 1999: 414), ambas con gran cantidad de ediciones.

Lo anterior se revela en Cuba a partir de la instauración en 1845 del Plan de instrucción pública para las islas de Cuba y Puerto Rico ${ }^{12}$, donde se incluye en el artículo $4^{\circ}$. del capítulo 1 la gramática castellana como una de las asignaturas que debían impartirse en la enseñanza elemental, lo cual queda cumplido en el programa ${ }^{13}$ ofrecido por el colegio San Severiano, y el texto objeto de análisis en este trabajo es una clara muestra.

Situación similar se observa en el continente ${ }^{14}$, aunque por razones diferentes, pues ya allí era una realidad la independencia en muchos de sus países, en varios de los cuales se habían creado academias correspondientes; no así en Cuba, donde en esos momentos se preparaba la llamada por José Martí guerra necesaria. Tal vez pueda ser esta una de las razones por la cual las gramáticas de la época producidas en Cuba no expresaban tampoco un esbozo de teoría lingüística diferente a lo ya conocido por las obras de la RAE, las cuales eran seguidas fielmente.

11 A esto se suma la incorporación a la gramática española de aspectos racionalistas procedentes de la Gramática de Port-Royal, junto con la orientación psicológico-empirista de Condillac y de los ideólogos (ibíd. 574).

12 Publicado en el periódico El Redactor, Santiago de Cuba, el viernes 28 de abril de 1845 . BNE.

13 Cfr. Cuaderno de Calificaciones diarias de Julio Severiano Hernández y García, (s.f),

${ }_{14}$ Cfr. el artículo de Esteban Lidgett en el que plantea que en el contexto del Congreso Literario hispanoamericano (1892) y la constitución de academias correspondientes en varios países "emerge la reivindicación del español peninsular en diversos órganos de difusión, desde la prensa diaria hasta los manuales escolares como una manera de preservar la lengua nacional" (2011: 115). 
El documento que aquí se presenta consideramos que no está incluido entre los contabilizados por Dihigo, por cuanto fue creado fuera de La Habana y por un maestro que presumimos, por referencias y otros documentos revisados, no estaba entre los reconocidos ${ }^{15}$ nacionalmente en ese momento; súmesele el hecho de que la escuela que dirigía radicaba en su casa, ubicada en Pozo del Rey 37 entre Cuartel de Pardos y Paraíso, en un barrio pobre de la ciudad, y que los niños que a ella asistían eran fundamentalmente negros.

Antes de adentrarnos en los elementos formales objeto de nuestro análisis, consideramos interesante realizar un comentario de las Dos palabras utilizadas como Prólogo a esta primera edición del libro, firmadas por Francisco Martínez Betancourt, quien, por lo que declara, fue maestro del autor.

En todo momento, Francisco Martínez enfatiza en su estatus en relación con el “joven D. Julio S. Hernández y García, meritísimo discípulo nuestro, el cual nos honra muy mucho, pidiéndonos estas dos palabras". Se siente honrado, pero entre líneas revela la honra que también debe sentir el joven autor al haber sido su alumno, al tiempo que establece su superioridad en relación con este:

La instrucción, dice Horacio, desarrolla el germen del talento.

Este pensamiento se nos ocurre ahora al examinar la obrita titulada "Brevísimas nociones de Analogía Castellana", la cual encontramos, á nuestra limitada inteligencia, no sólo aceptable para la enseñanza de párvulos, sino también para los elementales; y se nos ha ocurrido repito al ver el rápido adelanto en que se encuentra su autor, el joven D. Julio S. Hernández y García, (...)

Pues qué, ¿Napoleón no fué soldado que llegó á ser árbitro de los destinos de Europa?

¿Esopo no fué esclavo que podía haber enseñado á su amo?

¿Y Plácido ${ }^{16}$ no fué peinetero, que ha alcanzado celebridad merecida por su talento?

15 En las Actas capitulares, 124, 1892, se lee la Instancia de don Julio Severiano Hernández solicitando aumento de subvención al Ayuntamiento por falta de espacio. "Con la subvención mudaría a su familia a otra casa y dejaría esa sólo para los alumnos".

La calidad de la enseñanza de la escuela dirigida por D. Julio S. Hernández fue reconocida por la inspección realizada por una Comisión nombrada por la Junta Local de $1^{\text {a }}$ Enseñanza el 12 de junio de 1892 (Archivo Histórico Provincial de Santiago de Cuba (AHPSC), Fondo de Gobierno Municipal, legajo 227).

16 Gabriel de la Concepción Valdés (Plácido) (1809-1844), un poeta cubano. Creció pobre y prejuiciado por ser mulato. Fue el poeta de mayor aceptación y divulgación en Cuba, además de ser considerado uno de los iniciadores del criollismo y el siboneyismo en el movimiento 
Siga por el sendero de la instrucción el autor de este texto de Gramática, que nosotros le auguramos para el fin de la jornada, una justa reputación, dado el gusto con que maneja el ars bene dicendi de los filósofos latinos y resultado infalible de los que, como él, consagran sus días al estudio primordial de todas las ciencias, la Gramática.

$\mathrm{Cuba}^{17}, 1^{\mathrm{o}}$ de Septiembre de 1890.

La obra cumple con las regularidades que los autores consultados, dedicados a la gramaticografía, han relacionado (Cfr. García 2005; Domínguez 2010), es decir, su fin u objetivo es didáctico, tiene carácter meramente normativo, con modelos como es el caso de la conjugación según los verbos modelo, y usa la técnica de preguntas y respuestas, ajustándose de esa forma a la manera más generalizada en la época, muy relacionada con el escolasticismo que imperaba en la educación desde siglos anteriores.

Estamos, como ya hemos expresado, ante un manual dialogado, insertado en un método gramatical basado en el aprendizaje de conceptos y normas con sus excepciones (Sánchez 1992, 1997, apud García et al. 2015: 52), donde la información gramatical concreta se ofrece a la manera del catecismo, en forma de preguntas y sus respectivas respuestas.

Este método tiene su origen en las gramáticas erotemáticas medievales, inspiradas en el Ars Minor de Donato, y en la conversación catequística de las clases de religión del siglo XVI; más tarde, en el siglo XVII y principios del XVIII, se transfirió a prácticamente todas las asignaturas enseñadas en las escuelas. En el ámbito de la enseñanza gramatical, el hecho de que el Libro III de las Introductiones latinae de Nebrija siguiera en cualquiera de sus redacciones las pautas de una gramática erotemática muy probablemente contribuyó a la fortuna del método (cfr. Esparza 2000: 192, apud García et al. 2015: 53).

En este sentido resulta evidente el carácter facilitador del método erotemático que "persigue la comprensión inmediata del contenido metalingüístico formulado como una pregunta y no tanto la reflexión del alumno sobre la lengua" (ídem); idea que incluso fue asumida por la Academia en la octava edición de su Epítome.

lírico cubano. Fusilado el 28 de junio de 1844 en Matanzas por acusaciones de ser integrante de la Conspiración de la Escalera.

${ }_{17}$ Así era conocida la ciudad de Santiago de Cuba en el siglo XIX e incluso en épocas anteriores. 
No obstante, se debe tener en cuenta la idealización que se da de una relación asimétrica profesor-alumno como conversación instructiva, en la que cada uno asume su papel en función de la finalidad que se persigue a través de este método: la enseñanza escolar en un nivel inicial de formación.

Desde el punto de vista formal la obra se dedica:
A los Sres. Doctores
D. José Gómez de la Maza, D. Manuel Pruna Santa Cruz, D. Angel Norma y de las Cuevas, D. Ambrosio Grillo y Portuondo y
A los Maestros superiores
D. Francisco Martínez Betancourt y D. José Joviniano Alea y Castillo (...).

Todos, importantes figuras de Santiago de Cuba, como por ejemplo el Doctor en Medicina Ambrosio Grillo ${ }^{18}$ y el Maestro de Julio S. Hernández, D. Francisco Martínez Betancourt ${ }^{19}$, quien precisamente se encarga de realizar las palabras introductorias del texto.

A continuación vienen las Dos Palabras a las que se hizo referencia anteriormente y luego la Introducción, en la que a través de preguntas y respuestas se define la gramática castellana como: El conjunto ordenado de principios y reglas para hablar y escribir correctamente el castellano, donde se marca, por una parte, la necesidad del conocimiento de los principios y fundamentos -dígase en este caso: principios y reglas- de la lengua propia, ya no supeditada ni en los fines ni en los métodos a las lenguas clásicas; y, por otra, la preocupación tanto por la expresión oral como por la escritura, acciones modificadas por el adverbio correctamente ${ }^{20}$. Sin embargo, no hay explicación sobre lo que se consideraría hablar y escribir correctamente.

Y seguidamente, a través del mismo sistema, se refiere a las cuatro partes de la gramática: analogía, sintaxis, prosodia y ortografía, coincidiendo con lo planteado por Domínguez (2010: 139), división cuatripartita que parte de la asentada desde la Edad Media ${ }^{21}$, donde se mencionaban: etimología

18 Médico cubano, nacido en Santiago de Cuba, y fundador de la Liga Antituberculosa de Cuba. Presidente fundador del Colegio Médico de esta zona del país. Subvencionó durante el primer cuatrimestre la revista científica Finlay, Órgano Oficial del Colegio Médico de Santiago de Cuba. Fue alcalde de su ciudad natal desde 1908 hasta 1912.

19 Reconocido maestro en la época y miembro de la Junta local de $1^{\text {a }}$ enseñanza.

20 Esta idea se ofrece en las definiciones de gramática que aparecen a partir de la $6^{\mathrm{a}}$ edición de la GRAE de 1858 hasta la $11^{\text {a }}$ de 1867 (cfr. Martínez 2011: 601, nota 63).

21 Esta clasificación cuatripartita es resultado de la evolución de una propuesta anterior, como consecuencia de la aplicación de nuevos criterios en la definición de las categorías 
(por analogía) y las tres restantes; las cuatro respondían respectivamente a la palabra, oración, sílaba y letra, unidades básicas de las lenguas (cfr. Martínez 2011:616).

Esta correlación con otras palabras se repite en el texto donde según el autor, "la analogía enseña el valor y propiedad de las palabras"; la sintaxis, "la coordinación de las palabras para expresar los pensamientos"; la prosodia, "la verdadera pronunciación y acentuación de las letras, sílabas y vocablos" y la ortografía, "a emplear bien las letras de que se componen las palabras, con sus correspondientes signos de puntuación".

La Parte primera, dedicada a la ANALOGÍA, se inicia con la definición de oración como: "palabra o reunión de palabras con que expresamos un conjunto cabal" y la de palabra como: "cualquier sonido con que emitimos una idea".

Nótese que en la definición de oración se centra en su estructura formal y de cierta manera hace alusión a cuestiones significativas relacionadas con criterios lógicos o psicológicos; mientras que en la de palabra hace referencia a la secuencia fónica y al significado, no así a su constitución morfológica.

Al referirse a las partes de la oración, menciona diez: artículo, nombre sustantivo, nombre adjetivo, pronombre, verbo, participio, adverbio, preposición, conjunción e interjección, y enfatiza el hecho de que no son iguales, marcado por la diferencia que se centra en el carácter conjugable del verbo con relación al declinable del artículo, nombre sustantivo, nombre adjetivo, pronombre y participio, obviando, al menos a partir de la respuesta ofrecida, otras diferencias formales y funcionales de estas categorías de palabras gramaticales.

A continuación, dentro de la lógica de análisis, define la declinación como la posibilidad de "poder variar según sus accidentes o a ponerlas en diferentes casos" y menciona los seis casos existentes: nominativo, genitivo, dativo, acusativo, vocativo y ablativo, a la usanza de las declinaciones latinas, con lo cual se remite indudablemente a esta fuerte huella que sigue manteniéndose en la gramática y su enseñanza en esta época.

Luego comienza a detallar los diferentes accidentes gramaticales. Lo primero que trata es el número; se refiere a la definición del singular y el plural, como únicos números existentes en nuestra lengua, y para ello utiliza como ejemplos los sustantivos: gallina, mapa y escarificador (en singular

gramaticales, que se evidenció fundamentalmente en la sustitución del término etimología por analogía. La GRAE lo adoptó en su edición de 1796 y ya, en 1835, se prefería analogía en la mayoría de los textos sobre la gramática española (Martínez 2011: 616). 
y plural). Y posteriormente, a las diferentes reglas para la formación del plural a partir de la terminación de los nombres, poniendo también ejemplos muy esclarecedores: si el nombre termina en $e$ aguda o vocal breve (caña, cañas; café, cafés, mango, mangos ${ }^{22}$ ) o en $a ́$ o $i$ agudas o en consonante (quimbombó 23 , quimbombóes, borceguí, borceguies; nación, naciones, etc.), no olvida las excepciones como mamá, papá, chacó, maravedí y otros.

Resulta interesante cómo identifica de una manera muy clara los géneros (masculino y femenino) a partir de la variante sexuada; para ello ejemplifica para el masculino con nombres de varones (Angel, Ambrosio, Julio, Severiano, entre otros) y de animales machos (chivo, burro, buey, senserenico, etc.) y "el de objetos que no tienen sexo, se les puede anteponer el artículo el; como el bisturí, cepillo, chaleco, sombrero, etc.”. Para el femenino utiliza la misma técnica, nombres de mujeres como Jacobina, Josefa, Anita, Carmen, etc. y "animales hembras, gata, perra, mula, yegua"; $\mathrm{y}$ "el de objetos que no teniendo sexo, se les pueda anteponer el artículo $l a$, como: la navaja, la tohalla, la cinta).

En este apartado también aborda los otros cuatro géneros: el neutro, en los casos de "nombres de cosas no concretas ni determinadas faltas de plural, como: lo sabio, lo bello, lo inútil, lo digno, lo horroroso". El género epiceno lo define como aquel que se refiere a "los nombres de animales que con un mismo artículo y terminación, comprenden ambos sexos ${ }^{24}$ " (ejemplo: la pulga, la chinche, el alacrán y el lagarto, entre otros); mientras que el común de dos, lo destina para "aquellos nombres y cosas aplicables a personas que con una misma terminación y artículo comprenden los dos sexos" (ejemplo: $D$ y $D^{a}$ Loreto, el Virgen Francisco y Merced, el/la testigo,

22 Llama la atención el hecho de que el autor emplea palabras comunes utilizadas en la época, al alcance del público hacia el cual va dirigido el manual (niños), algunas de ellas llegan a nuestros días en el español hablado en Cuba (quimbombó), otras ya están en desuso (maravedí, borceguí).

23 Quingombó. M.: Planta herbácea originaria de África y cultivada en América. El fruto tierno se emplea en algunos guisos, dando una especie de gelatina que los espesa, y también en medicina. La planta, que es filamentosa, se emplea como textil (RAE, Diccionario de la lengua española, T I- II, vigésima segunda edición, Espasa Calpe, Madrid, 2001, p. 1882). Fernando Ortiz señala que se utiliza la voz en el Congo y que procede del kikongo o del lingala, para lo cual se basa en Hermenegildo Capello y Roberto Ivens (From Benguelato the Territory of Iacca), aunque también reporta su uso en yolofe (cfr. J Dard: Grammaire Yolofe, apud. Sergio Valdés 2013).

24 Aquí se hace referencia específicamente a los casos donde se aprecia una indiferencia respecto al género. En los ejemplos expuestos no se alude al género femenino o masculino de estos animales, sino a una designación genérica de la especie. 
etc.) y el ambiguo, a los casos en que indistintamente se utiliza la forma femenina o la masculina (ejemplo: el/la calor, el/la pared).

En relación con el artículo, le dedica todo un apartado: Del artículo y sus propiedades, en el que lo define como: "una parte de la oración que se antepone al sustantivo común ó genérico con el objetivo de anunciar su número y su género", lo clasifica "en determinante o determinado e indeterminante ó indeterminado", especifica sus formas (el (los), la (las), lo, un (unos), una (unas)) y muestra su declinación por género (masculino, femenino y neutro), que no es más que la manera en que pueden articularse sintácticamente dentro de la oración.

Además, menciona las contracciones al y del como "contracciones exigidas por el uso de los buenos escritores". Ofrece asimismo reglas para el uso u omisión del artículo.

El próximo acápite corresponde a Del nombre sustantivo y sus propiedades. De acuerdo con la lógica establecida en el libro de preguntas y respuestas se define y clasifica, primero en común o apelativo genérico y propio, con sus respectivos ejemplos: niño, escuela, gremio, sociedad, y Josefa, María, Guantánamo, Caney, y luego en: primitivos, derivados, patronímicos, simples, compuestos, verbales, colectivos, abstractos, partitivos, aumentativos, diminutivos y proporcionales; clasificaciones en las que mezcla criterios formales (primitivos/derivados, aumentativos, diminutivos, que también son derivados, simples/compuestos y colectivos) y significativos como los patronímicos y verbales (procedentes de verbos, lo que también guarda cierta relación con lo formal) e incorpora los que, según los ejemplos que cita, hacen referencia a pronombres numerales (los partitivos: un décimo, dos milésimas, cien vigésimos y los proporcionales: duplo, cuádruplo, quíntuplo).

Nuevamente recurre al uso de palabras conocidas y nombres propios comunes en la zona ${ }^{25}$, así como a la mención de lugares de la región ${ }^{26}$; por otra parte, los ejemplos no son extraídos de obras literarias ni de autoridades paradigmáticas en el uso de la lengua, sino del habla cotidiana, mucho más cercana a los destinatarios del libro: niños pobres de una región de Cuba alejada de la capital de la Isla.

En el segmento destinado al adjetivo, comienza marcando su función de incidente del sustantivo al definirlo como: "aquella parte de la oración

5 El Caney, poblado cercano a la ciudad de Santiago de Cuba.

26 Guantánamo, ciudad ubicada también en la región suroriental y próxima a Santiago de Cuba. 
que se junta al sustantivo para calificarle o determinarle"; los clasifica en modificativos o calificativos y determinativos, los cuales quedan esclarecidos a partir de los ejemplos: pobre, pequeño, lindo, para los primeros, mientras que los segundos son definidos como aquellos que "determinan al sustantivo sin expresar cualidad", por ejemplo, veinte, otra, todos. En cuanto a la función, se refiere a la determinación y a la calificación, en tanto, como las gramáticas de la época, coloca dentro del grupo de los adjetivos tanto a los adjetivos propiamente dichos (con su función calificativa) como a los pronombres en función adjetiva.

Interesante resulta la manera en que retoma el género, como una de las marcas de concordancia del adjetivo con el sustantivo y la explicación de los casos de adjetivos de una y dos terminaciones. Según el texto, en los "de una terminación", la concordancia la marca el morfema de género del sustantivo y, por el contexto, el adjetivo asume por supuesto el género del sustantivo (por ejemplo, los casos de género femenino, masculino e incluso el neutro a partir del adjetivo útil y su colocación como calificativo de los sustantivos niño, niña y el pronombre neutro $l o$ ); y en los adjetivos de "dos terminaciones", sí hay una marca morfológica explícita y pone como ejemplo las distinciones: lindo/linda, negro/negra.

Estos aspectos relacionados con el género aparecen vinculados a la manera en que se declina el adjetivo, respuestas en las que expresa detalladamente la marca morfológica masculina, femenina y neutra, e insiste en que "tiene solamente número singular y carece de vocativo".

Incluye, además como otra clasificación, los adjetivos modificativos y calificativos en: "las mismas que el sustantivo, exceptuándose los patronímicos, los abstractos y los colectivos determinados", y en "étnicos y gentilicios nacionales". Esta última división la explica a partir de los que denotan raza (por ejemplo, Europeo, Asiático, Americano, Africano) y nación, patria o naturaleza (ejemplo, guantanamera, bayamesa, cobrero, cubana). Estos últimos referidos, una vez más, a localidades de la región oriental donde también se encuentra la ciudad de Santiago de Cuba.

En relación con lo anterior, Domínguez (2010:117-118) afirma que los estudios lingüísticos realizados en Cuba en el siglo XIX se caracterizaron por la defensa de la identidad nacional, por ello no es extraño que la mayoría de los trabajos se dirigieran al análisis de la lengua regional, sus variantes e infidelidades ("infidencias", subraya la autora). Este texto, si bien no está, ni en su concepción ni en sus objetivos, dirigido a la variante regional, sí consideramos que su autor la toma en cuenta, al utilizar, como hemos demostrado, ejemplos de la vida cotidiana y de la lengua en uso en la región y, en ocasiones, en el país. 
Dentro de la clasificación de los adjetivos, además incluye los determinativos, los numerales cardinales y ordinales y desecha la función adjetiva de los posesivos, demostrativos e incluso indefinidos que ya había tomado como ejemplos al referirse a estos más arriba.

Asimismo expone los grados del adjetivo asumidos como otra clasificación y definidos como las "diversas maneras que tienen de calificar en grados distintos". Se refiere al positivo como el que "denota simplemente la cualidad", el comparativo se forma "comparando siempre" y el superlativo "anteponiendo el adverbio muy al positivo, o haciéndolo terminar en ísimo". Termina listando los 6 casos de adjetivos que presentan formas especiales de comparativo y superlativo.

En la sección destinada a los pronombres, los designa como "una parte de la oración que reemplaza al nombre sustantivo, evitando su repetición", con lo cual explicita que se circunscribe solamente a los pronombres en función sustantiva: personales, demostrativos, posesivos, relativos e indeterminados; pasa a explicar los personales, centrándose en "yo, tú, él", su alusión a las tres personas gramaticales correspondientes $\left(1^{\mathrm{a}}, 2^{\mathrm{a}}\right.$ y $\left.3^{\mathrm{a}}\right)$ "la que habla", "a quien se habla" y "cosa de quien se habla" y seguidamente pregunta: "¿Qué variantes resultan de la declinación de estos pronombres?", a lo cual responde a partir de las diferentes variantes pronominales que se corresponden con estas tres personas gramaticales en ambos números.

Los pronombres demostrativos son explicados como aquellos que "sirven para demostrar las cosas o las personas", son tres: este, ese y aquel, y ofrece su definición, en dependencia de la cercanía en relación con el que habla, a quien se habla y "la persona ó cosa que está distante de uno y otro", haciendo evidente alusión al carácter deíctico de estos pronombres. Por último, completa su explicación a partir de ejemplos contextualizados y declara las variantes genéricas y numéricas de cada uno de los demostrativos, como "variantes que resultan de la declinación".

Al pronombre posesivo lo denomina como aquel que "denota posesión o pertenencia" y menciona cinco: mío, tuyo, suyo, nuestro y vuestro. $\mathrm{Y}$ aclara lo siguiente: "Cuando los pronombres mío, tuyo y suyo ván ántes de un nombre, pierden por la figura de dicción apócope, el primero la ó y los otros, la sílaba yo, quedando convertidos en adjetivos posesivos". Ilustra con los siguientes casos: "mi lanceta, en lugar de mia lanceta", entre otros, según la persona gramatical y el número.

Concluye este apartado con "las terminaciones que resultan de las declinaciones de estos pronombres".

El pronombre relativo es definido como "el que se refiere a persona ó cosa ya expresada". Menciona cuatro: qué, cuál, quién, cuyo. 
Como variantes resultantes de la declinación menciona: el, la, lo, los, las (que), cuál(es), quien, quienes, cuyo, cuya, cuyos.

Seguidamente trata el pronombre indeterminado y lo define como "el que se pone en lugar de una persona ó cosa indeterminada" y ejemplifica con: fulano, zutano, alguien, nadie, cualquiera y quienquiera. Se detiene exclusivamente en las particularidades de alguien y nadie: "carecen de plural"; con ello hace referencia a particularidades gramaticales y por extensión significativas desde este punto de vista fundamentalmente.

En el caso específico de los indeterminados, no incluye dentro de la explicación diversos tipos de pronombres en esta serie tan compleja y variada, tales como: uno, alguno, ninguno, aquellos con carácter cuantitativo: todo, mucho, poco, otros, y también con carácter cuantitativo que se acercan a los adverbios como: bastante, demasiado, varios; otro y sus variantes genéricas y numéricas; demás; algo, nada y el distributivo cada.

Esta supresión puede deberse al hecho de que el libro estaba destinado a la instrucción primaria y por ende no era necesario un mayor grado de complejidad.

El verbo es "la parte más importante de todas las de la oración", al expresar "existencia, estado, acción o pasión de las personas ó cosas". Los divide en: primitivos o derivados y simples o compuestos, apelando a su estructuración morfológica y ante la pregunta "¿Qué es conjugar?", responde: "la variación del verbo según sus accidentes en modos, tiempos, números y personas".

Dentro de los modos, además de los ya establecidos, incluye el infinitivo, como aquel que "expresa la existencia ó acción sin designar el tiempo, el número y la persona, como buscar, leer, decir, dormir".

Los tiempos son "los que fijan la época de algún suceso": presente, pasado y futuro, haciendo alusión a la ubicación temporal de la realización verbal; pero los gramáticos ${ }^{27}$ "los han dividido en seis": presente, pretérito imperfecto, pretérito perfecto (que según ejemplos que expone en cada conjugación, agrupa al pretérito perfecto, indefinido y anterior, pretérito pluscuamperfecto, futuro imperfecto y futuro perfecto). En esta nomenclatura, centrada en el modo indicativo y sin poner ejemplos (salvo los que cita más adelante), se adhiere de manera general a la establecida por la Academia y no así a la desarrollada por Andrés Bello en América.

27 Este es uno de los pocos momentos en el libro en que se realiza una cita a alguna autoridad en la materia. 
A continuación aborda el número y las personas, marcados según él, por los pronombres personales (y no por el morfema gramatical indicado para ello).

Las conjugaciones son expuestas en sus características formales (dígase terminación), y como en los casos anteriores, se ofrecen ejemplos para cada una. Los verbos son divididos en seis clases: "sustantivo como ser, activo transitivo como amar, neutro como engordar, activo intransitivo como reir, en reflexivo como dignarse y en recíprocos como ellos se tutean o tutearse".

Esta clasificación mezcla diversos criterios: el tipo de predicado (o verbo) en el caso de las llamadas sustantivo, la transitividad o intransitividad y la reflexividad o reciprocidad, estos cuatro dentro de las construcciones predicativas (o de predicado verbal, opuesto a las llamadas por él sustantivas). No queda clara qué es para el autor la llamada clasificación de verbo en neutro, pues el ejemplo que cita (engordar) no alude a nada en específico. Llama letras radicales a la raíz o morfema lexical de los verbos y a continuación pone ejemplos de las tres conjugaciones:

En el caso del llamado modo infinitivo, incluye dentro de este:

\author{
Presente: amar \\ Pretérito: haber amado \\ Futuro: haber de amar \\ Gerundio: amando \\ Participio: amado
}

Dentro del pretérito perfecto, según los ejemplos, agrupa: “yo amé, he amado ó hube amado" (como ya se explicó anteriormente).

En cuanto al imperativo, son muy importantes las marcas:

Ama tú, ame él (para el singular) y amemos nosotros, amad vosotros y amen ellos.

Obsérvese cómo incluye la tercera persona y su marca tomada del presente del subjuntivo, al igual que la primera persona del plural con igual forma tomada del subjuntivo presente. En este caso podríamos estar ante un acercamiento a la variante americana, específicamente la cubana, donde se utilizan dos formas de tratamiento para el singular: familiar ( $t u$ ) y de respeto (usted), que para el imperativo utilizan: Ama tú y ame usted.

El participio puntualizado como "aquella parte de la oración que participa de las cualidades de adjetivo y verbo, procediendo siempre de este último", lo divide en "activo ó de presente y en pasivo ó de pretérito". Señala que el primero es "el que termina en ante si es de la primera conjugación del 
verbo": "de amar, amante, de tratar, tratante (...). Y si es de la segunda y tercera conjugación en ente o iente: de nacer, naciente; de salir, saliente (...)". Adviértase cómo en esta clasificación sigue los patrones de la gramática latina al utilizar la forma en -ante, -ente o -iente. Dentro de la segunda clasificación, se detiene en ejemplificar, según las terminaciones, los casos de participios regulares e irregulares: "temer, temido, de cojer cojido (...) de morir, muerto, de ver, visto (...)".

El adverbio lo define como "una parte de la oración indeclinable que modifica el verbo", sin hacer alusión a la posibilidad que tiene el adverbio de modificar también a los adjetivos y a otros adverbios. Los divide, por su forma, en simples (aquí, allá, hoy) y compuestos (anteayer, además, torpemente). Asimismo, declara que existen nueve clases de adverbios: lugar, tiempo, modo, comparación, orden, afirmación, negación y duda; clasificación que de manera general se ha mantenido hasta nuestros días. Da definiciones y pone ejemplos en cada caso.

Dedica también un acápite a la preposición "una parte indeclinable de la oración que sirve para señalar la relación que tienen entre sí dos palabras u oraciones". De esta manera hace alusión al carácter de relator que tiene esta categoría de palabra gramatical.

Las divide en propias o separables, que "se usan en composición o fuera de ellas: las que normalmente conocemos como tal" e impropias o inseparables, las que "solo pueden usarse en composición: abs (abstraer), ex (exministro), in (indigno), infra (infrascrito), sub (submarino). De acuerdo con los ejemplos de la última clasificación se refiere a prefijos que ya han pasado a formar parte de la constitución morfológica de las palabras.

La conjunción es explicada como "aquella parte indeclinable de la oración que sirve para expresar las relaciones que hay entre dos pensamientos u oraciones", y al igual que en el caso de las preposiciones, también marca el carácter de relator de esta categoría. Las divide en simples (y, ó, ni, que) y compuestas (se componen de dos o más palabras: es decir, a fin de que, por lo tanto), agrupadas en diez clases: copulativas, disyuntivas, adversativas, condicionales, causales, comparativas, continuativas, explicativas, finales e ilativas. La definición y ejemplificación de las tres primeras coincide con las que actualmente se conocen.

Las condicionales, causales comparativas y finales, son las que contribuyen a establecer relaciones precisamente de condición, causa y comparación y finalidad. Las continuativas marcan una continuación de la idea (por tanto, en efecto, así que, además). Como explicativas menciona: verbi gracia, a saber, esto es, por ejemplo; las cuales, según el autor, "sirven para desenvolver con más facilidad los pensamientos".

Las ilativas son las que llamamos hoy consecutivas. 
Se refiere también a las frases conjuntivas como "conjunto de palabras que unidas tiene un significado de conjunción" (mientras que, entretanto que, a menos que, dado que).

Por último, no deja de mencionar las interjecciones, también parte invariable de la oración "que expresa vivamente las afecciones repentinas del alma", con lo que marca la funcionalidad pragmática de estas partículas, por ejemplo: ¡hola!, jest!, ¡bravo!, ¡cáspita!, ¡tate!, ijo!, ¡bien!, jay!, ¡oh!, ¡bah!, ipuf!, ;chitón!, algunas de ellas ya en desuso.

Muy interesante el apartado denominado Figuras de dicción (o metaplasmo): "ciertas licencias autorizadas por el uso de los buenos escritores en virtud de la cual, se añaden o quitan letras ó sílabas a algunas palabras". Considera ocho: prótesis, epéntesis, metátesis, paragoge, sinalefa, aféresis, síncopa y apócope; de acuerdo con D. Julio Severiano, las últimas cuatro son las más utilizadas, mientras que las cuatro primeras quedan para la poesía o el estilo familiar.

A continuación define y ejemplifica: la sinalefa (del, al, esotro, estotro), la aféresis (noramala por en hora mala), la síncopa (Navidad por Natividad, antier por antes de ayer) y el apócope (mi por mío, tu por tuyo); esto es, en los casos del posesivo antepuesto al sustantivo.

El texto termina con la parte titulada Del análisis, donde comienza definiendo el análisis analógico o gramatical como el que "explica á qué parte de la oración pertenecen todas las palabras de un escrito o lo que es lo mismo el que descompone en partes un todo" y, tomando el ejemplo $E l$ alumno aplicado solo recibe premios, presenta su propuesta de análisis a partir de la descripción de cada uno de los componentes de la oración, según su orden de aparición y sustentado en toda la explicación desarrollada en la parte anterior, siempre a partir del sistema de preguntas y respuestas.

\section{CONCLUSIONES}

Los estudios sobre historiografía lingüística en Cuba y en especial los referidos a la gramática escolar, aún precisan de un impulso que lleve a nuevos descubrimientos y a la determinación de regularidades y particularidades que puedan contrastarse con otros ámbitos hispánicos y en el propio país, lo cual sería provechoso para esta rama de la lingüística.

Durante el siglo XIX se elaboraron y publicaron en Cuba varios textos de gramática castellana dirigidos a la enseñanza escolar; en su mayoría 
siguieron las normas de la GRAE y no representaron un intento por plasmar o estudiar la variante cubana de la lengua, además de carecer de teorizaciones sobre la disciplina.

Brevísimas nociones de Analogía castellana (1891) destaca, en nuestra consideración, por la sencillez en la exposición de los conocimientos sin perder el valor científico ni abandonar su carácter prescriptivo. Las explicaciones ofrecidas por el método de preguntas y respuestas, a la usanza de las gramáticas de la época, tienen valor práctico, mientras que el estilo es simple y el tono coloquial, ajustado a la edad y el nivel de los educandos que utilizarían el libro.

La presentación de las distintas categorías sigue el modelo de la gramática latina, se enuncian a partir de la preposición $D e+$ el tema que se abordará. Por otro lado, a diferencia de otros textos, que extraían sus ejemplos de obras literarias o autores considerados autoridades, utiliza los propios del uso y del conocimiento habitual de los educandos.

Por último, el texto abordado en este estudio no constituye un tratado sobre teoría gramatical, tampoco era esa la intención del autor, pero sí tiene valor documental e histórico porque encierra una codificación y reflexión lingüística, así como las prácticas de regulación de las formas comunicativas, los patrones de conciencia lingüística y ofrece información sobre la enseñanza de la lengua materna.

\section{REFERENCIAS BIBLIOGRÁFICAS}

Alpízar Castillo, Rodolfo. 1989. Apuntes para la historia de la lingüistica en Cuba. La Habana: Editorial de Ciencias Sociales.

Bello, ANDrés. 1995. Gramática: gramática de la lengua castellana destinada al uso de los americanos. Prólogo de Amado Alonso. Biblioteca virtual Miguel de Cervantes. Edición digital a partir de Obras completas. Tomo Cuarto, $3^{\mathrm{a}}$ ed., Caracas: La Casa de Bello, Disponible en http://cervantesvirtual.com/servlet/SirveObras/04694925499104944157857/ index.htm, consultado 15 de julio de 2015.

Domínguez Hernández, Marlen. 2010. La voz de los otros. La Habana: Centro de Estudios Martianos. Colección Ala y Raíz.

Fondo GoBierno Municipal, legajo, 227. Relativo a la reunión en la casa que ocupa la escuela san Severiano de la Comisión nombrada por la Junta Local de $1^{a}$ Enseñanza, 1892-6-12. Archivo Histórico Provincial de Santiago de Cuba (AHPSC).

García Folgado, María José. 2005. La Gramática española y su enseñanza en la segunda mitad el siglo XVIII y principios del XIX (1768-1815). Tesis doctoral dirigida por $\mathrm{D}^{\mathrm{a}}$. $\mathrm{M}^{\mathrm{a}}$. José Martínez Alcalde. Valencia: Universidad de Valencia.

García Folgado, M. J.; E. Montoro y C. Sinner. 2015. El diálogo en la enseñanza de los conceptos gramaticales: método catequístico, diálogo instructivo y debate crítico. En Brumme, Jenny; López Ferrero, Carmen (eds.). La ciencia como diálogo entre teorías, textos y lenguas, pp. 47-64. Berlín: Frank \& Timme. 
Hernández y García, Julio Severiano. 1891. Brevísimas nociones de Analogía Castellana. Primera edición. Santiago de Cuba: Imprenta de Juan E. Ravelo. (s.f), Cuaderno de calificaciones diarias. Santiago de Cuba: Imprenta El Arte. 1892. Nuevas tablas de cuentas para párvulos. Santiago de Cuba: Imprenta El Arte.

LidGetT, EsteBAn. 2011. Gramática escolar y políticas lingüísticas en la Argentina: un análisis de la Gramática de la lengua castellana (1893) de Baldmar Dobranich y Ricardo Monner Sans. Revista argentina de historiografia lingüistica, III, 2: 109-132. Disponible en www. rahl.com.ar, consultado 24 de junio de 2015.

Martínez Gavilán, Dolores. 2011. El campo de la gramática española y sus partes en el siglo XVIII. En J. J. Gómez Asencio (ed.), El castellano y su codificación gramatical, vol. III: De 1700 a 1835. Instituto Castellano y Leonés de la Lengua, pp. 571-630. Disponible en http://www.gruposincom.es/mariadoloresmartinezgavilan/El $\% 20$ campo $\% 20 \mathrm{de} \% 201 \mathrm{a} \% 20$ Gramatica\%20espanola.pdf, consultado 24 de junio de 2015.

Martínez Martínez, Rafael. 1983. Juan Miguel Dihigo: gran lingüista cubano. La Habana: Editorial Letras cubanas.

Plan general de instrucción pública para las islas de Cuba y Puerto Rico (1845). El Diario El Redactor. Santiago de Cuba, viernes 28 de abril, pp. 4-5.

Portuondo Zúñiga, Olga y Joan Rovira S. J. 2000. El Colegio Seminario San Basilio Magno. Santiago de Cuba: Editorial Oriente.

Torres Martínez, Marta. 2012. La enseñanza de la formación de palabras en la gramática escolar académica (1857-1949). Revista argentina de historiografía lingüística IV, 1: 51-78. Buenos Aires. Disponible en www.rahl.com.ar, consultado 24 de junio de 2015.

Valdés Bernal Sergio. 2013. La hispanización de América y la americanización de la lengua española. La Habana: Editorial UH.

Zamora Vicente, Alonso. 1999. Historia de la Real Academia Española. Madrid: Espasa Calpe. 